\title{
Infant feeding practice and associated factors of HIV positive mothers attending prevention of mother to child transmission and antiretroviral therapy clinics in Gondar Town health institutions, Northwest Ethiopia
}

Dagnachew Muluye*, Desalegn Woldeyohannes, Mucheye Gizachew and Moges Tiruneh

\begin{abstract}
Background: It has been estimated that 430,000 children under 15 years of age were newly infected with HIV in 2008, and more than $71 \%$ are living in sub-Saharan Africa. In the absence of intervention to prevent mother-tochild transmission, $30-45 \%$ of infants born to HIV-positive mothers in developing countries become infected during pregnancy, delivery and breastfeeding. The aim of this study was to assess infant feeding practice and associated factors of HIV positive mothers attending prevention of mother to child transmission and antiretroviral therapy clinics of Northwest Ethiopia.
\end{abstract}

Methods: Institution based cross sectional study was conducted from January to May 2011 among all HIV positive mothers with less than two years old child attending prevention of mother to child transmission and antiretroviral therapy clinics in Gondar Town health institutions. A structured pre-tested questionnaire using interview technique was used for data collection. The data was entered and analyzed using SPSS version 16 statistical package.

Results: A total of 209 HIV positive mothers were included in the study. Of these, 187 (89.5\%) had followed the recommended way of infant feeding practice while significant percentage (10.5\%) had practiced mixed breast feeding. In multivariate analysis, disclosure of HIV status with their spouse, insufficient breast milk and occupational status were found to be independently associated ( $p$-value of $<0.05$ ) with recommended infant feeding practice. Lack of resource, stigma of HIV/AIDS, and husband opposition were also obtained as factors that influenced choice of infant feeding options by respondents.

Conclusions: Higher proportion of respondents used the recommended way of infant feeding practice by WHO as well as by Ethiopian Ministry of Health. However, mixed feeding in the first 6 months of age, an undesirable practice in infant feeding, were reported in this study. Infant feeding education that is aligned to national policy should be strengthened in primary health care, particularly in situations where prevention of mother to child transmission of HIV is prioritized.

\footnotetext{
* Correspondence: fetenemulu24@gmail.com

Department of Microbiology, Immunology and Parasitology, College of

Medicine and Health Sciences, University of Gondar, Gondar, Ethiopia
} 


\section{Background}

Approximately 430,000 children under 15 years of age were newly infected with Human Immunodeficiency Virus (HIV) in 2008, and more than $71 \%$ are living in sub-Saharan Africa [1]. Without intervention to prevent mother-to-child transmission, 30-45\% of infants born to HIV-positive mothers in developing countries become infected during pregnancy, delivery and breastfeeding [2]. The availability of anti-retroviral therapy (ART) during the last trimester of pregnancy and delivery through prevention of mother to child transmission (PMTCT) program reduces transmission of HIV during pregnancy, labor and delivery from $10 \%$ to $20 \%$ [3], but it does not solve the problem of infant feeding which is responsible for as much as 5-20\% of infections [2]. In sub-Saharan Africa, mother-to-child transmission (MTCT) of HIV is responsible for about $90 \%$ of HIV infections in children, and about half of these pediatric infections are thought to have been acquired through breastfeeding [4].

The Joint United Nations Program on HIV/AIDS (UNAIDS) and two of its partners (UNICEF and WHO) recommend that HIV-infected mothers should avoid breastfeeding only when replacement feeding is affordable, feasible, acceptable, sustainable, and safe (AFASS). Non breast-fed children born to HIV positive women are at less risk of illness and death only if they can be ensured uninterrupted access to nutritionally adequate breast milk substitutes that are safely prepared [5]. Exclusive replacement feeding (ERF) can reduce HIV-transmission, but is also associated with morbidity related to diarrhoea and respiratory infections. Exclusive replacement (formula) feeding is the most widely used and effective method to prevent MTCT of HIV-1 through breastfeeding in resource-rich settings and is recommended in situations in which this is AFASS [6-8].

Exclusive breast feeding by HIV-infected mother, when compared to partial breastfeeding or mixed breast feeding $(\mathrm{MBF})$, has been shown to be associated with a reduced risk of transmission in the early months of postpartum [9], and may confer a continued lower risk of transmission in babies continuing to breastfeed from 618 months $[10,11]$. According to the recent guidelines of WHO, when ARVs are not available, mothers should be counseled to exclusively breastfeed in the first six months of life and continue breastfeeding thereafter unless environmental and social circumstances are safe for, and supportive of, replacement feeding [12]. Mixed Breast feeding during the first month of life and breast feeding duration are strong determinants of HIV transmission [13]. The fact that EBF carries a significantly lower risk (almost half the risk) of MTCT of HIV than mixed feeding is not surprising because the beneficial immune factors of breast milk are probably counteracted by the damage to the infant's gut wall by contaminants or allergens in mixed feeds [14].

In a cross sectional study conducted in Addis Ababa, Ethiopia, the proportion of HIV positive mothers who fed their infants ERF, EBF and MBF were 46.8\%, 30.6\%, and $15.3 \%$, respectively. The predictors for choosing ERF were mode of delivery, household income and disclosure of HIV status to spouse. The predictor for EBF was mode of delivery while for MBF, disclosure of HIV status to spouse, parental infant feeding attitude and infant illnesses were the predictors. Furthermore, sticking to mothers' informed safer feeding options is challenged by some social factors [15].

With the rising prevalence rate of HIV/AIDS, over 200,000 children under-five are HIV positive in Ethiopia. The risk of transmission varies with the duration of breastfeeding, but it is estimated to be about $10-20 \%$ for those breastfed for two years [16]. However there is a dearth of literature in the study area particularly in Gondar referral teaching hospital, which is supposed to serve around four millions people coming from and neighboring regions. Therefore, this study has assessed the infant feeding practice of HIV positive mothers including the determinants, and provide evidence-based information that can be used by concerned bodies so that mother to child transmission of HIV virus through breast feeding can be decreased.

\section{Methods}

\section{Study design, area and period}

A cross-sectional study was conducted in Gondar Town PMTCT and ART health institutions, Northwest Ethiopia from January to May, 2011. Gondar town is located in North Gondar zone of Amhara regional state, Northwest Ethiopia $737 \mathrm{~km}$ far from the capital, Addis Ababa. Gondar has a total population of 206, 987 and out of these $52.6 \%$ are females and $47.4 \%$ are males.

\section{Target population and study population}

All HIV positive mothers with less than two years old child attending PMTCT and ART clinics in Gondar Town governmental health institutions.

\section{Sampling procedures}

All (209) HIV positive mothers with less than two years old child attending PMTCT and ART clinics in Gondar Town governmental health institutions were recruited. Those who fulfilled the inclusion criteria were interviewed during their visit to PMTCT and ART clinics.

\section{Operational definitions}

$\square$ Exclusive breast feeding - Giving the infant no other food or drink, not even water, apart from 
breast milk (including expressed breast milk), with the exception of drops or syrups consisting of vitamins, mineral supplements or prescribed medicines up to six months.

$\square$ Mixed breast feeding - Breastfeeding with the addition of fluids, solid feeds and non-human milks in the first 6 months of age.

$\square$ Exclusive replacement feeding - The process of feeding a child who is not receiving breast milk with a diet that provides all the nutrients the child needs, until the child is fully fed on family foods.

$\square$ Recommended infant feeding practice: those who practiced either exclusive breast feeding or exclusive replacement feeding.

$\square$ Not Recommended: those who practiced mixed breast feeding.

$\square$ Kebele: lowest administrative unit.

\section{Data collection procedures}

Data from all the participants were collected by 4 data collectors and the investigator. The data collectors were selected by their previous experience and education level holding bachelor degree in nursing and one with diploma nurse. They were provided with training on the process and objective of data collection by the investigator. Data was collected using pretested structured questionnaire based interview which includes full details of infant feeding practice and factors likely to influence infant feeding practice of HIV positive mothers. The interview was conducted during their follow up visit of the health institutions. Appropriate modifications were made after analyzing the pre-test result before the actual data collection. The questionnaire was first prepared in English then translated to local language (Amharic).

\section{Data analysis}

The returned questionnaires were checked for completeness, cleaned manually and entered and analyzed using SPSS version 16 statistical package. Data were summarized using frequency tables and pie charts. Backward Stepwise logistic regression model was fitted to identify different determinants of infant feeding practice. Standard techniques for model checking, including the Hosmer-Lemeshow goodness of fit test, were carried out to determine the adequacy of the regression model. Statistical significance was inferred at P-value $<0.05$.

\section{Ethical considerations}

This study was approved by Ethical review committee of University of Gondar, College of Medicine and Health sciences, Department of Microbiology, Immunology and Parasitology. Informed consent was obtained from each mother prior to study participation. In order to keep confidentiality of any information provided by study subjects, the data collection procedure were anonymous.

\section{Results}

\section{Socio-demographic characteristics}

A total of 209 HIV positive mothers participated in the study. Of these, 200 (95.7\%) were from urban and the rest from rural kebeles. The age of mothers ranges from 18-45 years with an average and standard deviation (SD) of 28.6 and 4.34, respectively. Among the study subjects 189 (90.4\%) were Orthodox Christian while 20 (9.6\%) were Muslim. The majority of the participants 165 (78.9\%) were married and $100(47.8 \%)$ had no formal education. Out of the total study participants 121 (57.9\%) were housewives followed by 60 (28.7\%) daily laborers. Majority of the participants 161 (77.2\%) had a monthly income of less than or equal to 500 Ethiopian birr. The mean age of the infants was 9 months (SD = 5.8 ) and $54.5 \%$ were males [Table 1 ].

\section{Infant feeding practice and other HIV related concerns}

The majority 189 (90.4\%) of the respondents gave birth between thirty eight and forty eight weeks of gestational

Table 1 Socio demographic characteristics of the study subjects attending PMTCT and ART clinics in Gondar town health institutions from January to May, 2011

\begin{tabular}{|c|c|c|c|}
\hline \multicolumn{2}{|c|}{ Characteristics } & \multirow{2}{*}{$\begin{array}{l}\text { Frequency } \\
34\end{array}$} & \multirow{2}{*}{$\begin{array}{l}\text { (\%) } \\
16.3\end{array}$} \\
\hline Age of mother & $18-24$ & & \\
\hline & $25-29$ & 88 & 42.1 \\
\hline & $30-34$ & 58 & 27.8 \\
\hline & $35+$ & 29 & 13.8 \\
\hline \multirow[t]{2}{*}{ Religion } & Orthodox & 189 & 90.4 \\
\hline & Muslim & 20 & 9.6 \\
\hline \multirow[t]{2}{*}{ Residence } & Urban & 200 & 95.7 \\
\hline & Rural & 9 & 4.3 \\
\hline \multirow[t]{2}{*}{ Marital status } & Married & 165 & 78.9 \\
\hline & Single & 44 & 21.1 \\
\hline \multirow[t]{3}{*}{ Educational status } & No formal education & 100 & 47.8 \\
\hline & Primary education & 56 & 26.8 \\
\hline & Secondary and above & 53 & 25.4 \\
\hline \multirow[t]{4}{*}{ Occupational status } & Housewife & 121 & 57.9 \\
\hline & Daily laborer & 60 & 28.7 \\
\hline & Government worker & 14 & 6.7 \\
\hline & $\begin{array}{c}\text { Private/merchant, farmers, } \\
\text { others }\end{array}$ & 14 & 6.7 \\
\hline \multirow{4}{*}{$\begin{array}{l}\text { Income (in Ethiopian } \\
\text { birr) }\end{array}$} & $<=200$ & 67 & 32.0 \\
\hline & $201-300$ & 41 & 19.6 \\
\hline & $301-500$ & 53 & 25.4 \\
\hline & $>501$ & 48 & 23.0 \\
\hline
\end{tabular}


age (term), $18(8.6 \%)$ of the respondents had post term birth, and only $2(1 \%)$ had pre-term birth. Among these 186 (89\%) gave birth at health institutions, 13 (6.2\%) gave birth at home with birth attendants and the rest gave birth at home without birth attendants. From the total respondents, 167 (79.9\%), 25 (12\%), 15 (7.1\%) and 2 (1\%) had spontaneous vaginal delivery, Cesarean section delivery, Episiotomy and instrumental delivery, respectively.

Among the respondents 138 (66\%) and 71 (34\%) are on ART and not on ART, respectively. Of the 71 respondents who were not on ART, 46 (64.8\%) had taken Neverapin drug starting from 28 weeks of gestational age, $3(4.2 \%)$ had taken a week before labor, 9 (12.7\%) had taken during labor and 13 (18.3\%) had never taken Neverapin drug.

One hundred eighty three $(87.6 \%)$ of the respondents had free discussion or disclosure about their HIV status with their spouse while $26(12.4 \%)$ had not disclosed their HIV status with their spouse. Of the participants $137(65.6 \%)$ had free discussion or disclosure of their HIV status with their family and $72(34.4 \%)$ had not disclosed. One hundred twenty two (58.4\%), 116 (55.5\%), 22 (10.5\%), 8 (3.8\%), and $6(2.9 \%)$ of the respondents stated that they had got the information about infant feeding from nurses, counselors, mass media, their families and their friends, respectively. Only 4 (1.9\%) of the respondents said that they had never got advice on infant feeding at all. Out of the total respondents, 193 (92.3\%), 8 (3.8), 4 (1.9\%), $3(1.4 \%)$ and 1 (\%) knew that MTCT of HIV virus can occur during pregnancy, delivery and breast milk feeding; during delivery and breast milk feeding; only during delivery; only during breast milk feeding and only during pregnancy and delivery, respectively.

Eighty two (39.2\%) of the respondents considered that EBF is the only infant feeding option while 64 (30.6\%) of the respondents considered that EBF, ERF, heat treated milk and wet nursing are infant feeding options of HIV positive mothers. Twenty nine (13.9\%) of the respondents said that EBF, ERF and heat treated milk are infant feeding options of HIV positive mothers while $9(4.3 \%)$ of the respondents said that ERF is the only infant feeding option.

One hundred eighty-seven (89.5\%) of the study participants had followed EBF and ERF practice while significant percentage $(10.5 \%)$ of the study participants had practiced mixed feeding [See Figure 1]. One hundred seventy two $(82.3 \%)$ of the respondents had initiated breast feeding within an hour of delivery and 37 (17.7\%) of the respondents had not initiated breast feeding within one hour of delivery. One hundred seventy-five (83.8\%) of the study subjects had practiced EBF for their infants and $12(5.7 \%)$ had practiced ERF and no one was reported to practice heat treated milk and wet nursing. The majority of the respondents 138 (66\%) use cup for

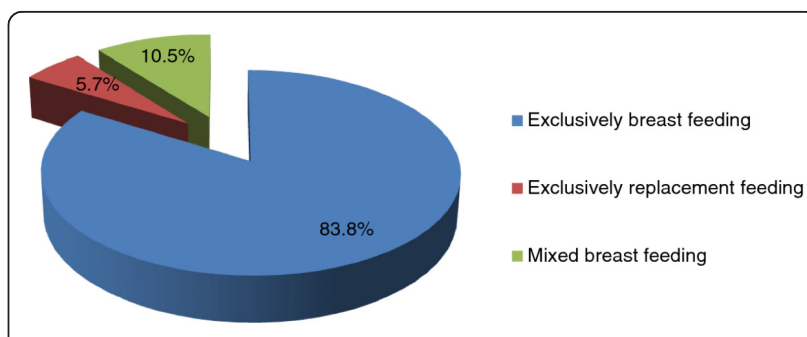

Figure 1 Percentage of infant feeding practice of HIV positive mothers attending PMTCT and ART clinics in Gondar town health institutions from January to May, 2011.

infant feeding while others 57 (27.3\%) and 14 (6.7\%) use bottle feeding and spoon feeding, respectively. Sixtyseven (32.1\%), 27 (12.9\%), 24 (11.5\%) and 20 (9.6\%) of the respondents said that availability of supply, stigma of HIV/AIDS, insufficient breast milk and husband opposition had affected their infant feeding option, respectively.

\section{Factors affecting infant feeding practice}

In logistic regression [see Table 2], place of delivery and disclosure of HIV status with their spouse were found to have association ( $\mathrm{p}$-value $<0.05$ ) for those who practiced recommended way of infant feeding practice (EBF and ERF) with COR $=4.98$ (95\% CI $=1.77-14.01)$, COR $=3.13(95 \% \mathrm{CI}=1.09-8.91) \mathrm{COR}=29.36(95 \% \mathrm{CI}=$ 2.91-296.4). In multivariate analysis, disclosure of HIV status with their spouse, insufficient breast milk and occupational status were found to be independently associated (p-value $<0.05$ ) with recommended way of infant feeding practice (EBF and ERF) AOR = 7.7 (95\% $\mathrm{CI}=1.1-53.97), \mathrm{AOR}=0.14(95 \% \mathrm{CI}=0.03-0.65), \mathrm{AOR}$ $=14.63(95 \% \mathrm{CI}=1.36-156.40)$. Mothers who disclose their HIV status to spouse were 7.7 times more likely to have recommended way of infant feeding practice and those daily laborers were 14.6 times more likely to have recommended way of infant feeding practice than private/merchants. Presence of insufficient breast milk was $85.7 \%$ times less likely to have recommended way of infant feeding practice.

\section{Discussion}

In this study, the proportion of mothers practicing EBF (83.7\%) for the first 6 months of age was comparatively higher than the findings reported from Nigeria (68.3\%), Uganda (24\%), India (44\%) and South Africa (35.6\%) [17-20] and the proportions of mothers practicing ERF (5.7\%) was lower than reported from South Africa (50\%), India (44\%), and Nigeria (31.7\%) [17-19]. This might be due to the culture of feeding habit of the Ethiopian mothers to their children than giving replacement feeding as well as the availability of resources to practice ERF. The proportion of mothers practicing EBF was also comparatively higher than what was reported 
Table 2 Impact of selected socio-demographic and other characteristics on infant feeding practice of HIV positive mothers attending PMTCT and ART clinics in Gondar town health institutions from January to May, 2011

\begin{tabular}{|c|c|c|c|c|c|}
\hline \multirow[t]{2}{*}{ Variables } & \multicolumn{2}{|c|}{ Infant Feeding Practice } & \multicolumn{2}{|c|}{ OR $(95 \% \mathrm{Cl})$} & \multirow[t]{2}{*}{$P$ value } \\
\hline & Recommended (\%) & Not recommended (\%) & Crude & Adjusted & \\
\hline \multicolumn{6}{|l|}{ Age } \\
\hline $18-24$ & $28(82.4)$ & $6(17.6)$ & 1 & 1 & \\
\hline $25-29$ & $82(93.2)$ & $6(6.8)$ & $.34(.10-1.14)$ & $.22(.04-1.18)$ & \\
\hline $30-34$ & $50(86.2)$ & $8(13.8)$ & $.74(.23-2.37)$ & $.85(.16-4.28)$ & \\
\hline $35+$ & 27(93.1) & $2(6.9)$ & $.34(.06-1.86)$ & $.40(.05-3.14)$ & \\
\hline \multicolumn{6}{|l|}{ Residence } \\
\hline Urban & 179(89.5) & $21(10.5)$ & $1.06(.12-8.94)$ & $.99(.07-12.66)$ & \\
\hline Rural & $8(88.9)$ & $1(11.1)$ & 1 & 1 & \\
\hline \multicolumn{6}{|l|}{ Religion } \\
\hline Orthodox Christian & 170(89.9) & 19(10.1) & $1.57(.42-5.88)$ & $2.50(.43-14.49)$ & \\
\hline Muslim & $17(85.0)$ & $3(15.0)$ & 1 & 1 & \\
\hline \multicolumn{6}{|l|}{ Marital status } \\
\hline Married & 149(90.3) & $16(9.7)$ & $1.47(.53-4.01)$ & $.79(.13-4.75)$ & \\
\hline Single & 38(86.4) & $6(13.6)$ & 1 & 1 & \\
\hline \multicolumn{6}{|l|}{ Educational status } \\
\hline No formal education & 89(89.0) & $11(11.0)$ & $1.03(.35-2.96)$ & $3.08(.60-15.69)$ & \\
\hline Primary education & $51(91.1)$ & $5(8.9)$ & $1.30(.373-4.55)$ & $2.80(.483-16.23)$ & \\
\hline Secondary and above & 47(88.7) & $6(11.3)$ & 1 & 1 & \\
\hline Occupational status & & & & & 0.026 \\
\hline House wife & 108(89.3) & 13(10.7) & $2.26(.55-9.19)$ & 4.64(.66-32.26) & \\
\hline Daily laborer & $54(90.0)$ & $6(10.0)$ & 2.45(.53-11.3) & $14.63(1.36-156.4)^{*}$ & \\
\hline Government/Private worker/merchants & 25(89.3) & $3(10.7)$ & 1 & 1 & \\
\hline \multicolumn{6}{|l|}{ Monthly income } \\
\hline$<=200$ & $55(82.1)$ & 12(17.9) & $.41(.12-1.38)$ & $.53(.11-2.58)$ & \\
\hline $201-300$ & $38(92.7)$ & $3(7.3)$ & $1.15(.24-5.47)$ & $1.60(.23-10.95)$ & \\
\hline $301-500$ & $50(94.3)$ & $3(5.7)$ & $1.51(.32-7.14)$ & 3.73(.52-26.32) & \\
\hline$>501$ & 44(91.7) & $4(8.3)$ & 1 & 1 & \\
\hline \multicolumn{6}{|l|}{ Place of delivery } \\
\hline Health institution & 171(91.9) & $15(8.1)$ & $4.98(1.77-14.01)^{*}$ & $2.26(.47-10.88)$ & \\
\hline At home & 16(69.6) & $7(30.4)$ & 1 & 1 & \\
\hline Disclosure of HIV status to spouse & & & & & 0.039 \\
\hline yes & 167(91.2) & 16(8.8) & $3.13(1.09-8.91) *$ & $7.74(1.11-53.97) *$ & \\
\hline no & 20(76.9.5) & $6(23.1)$ & 1 & 1 & \\
\hline \multicolumn{6}{|l|}{ Disclosure of HIV status to family } \\
\hline yes & 124(90.5) & $13(9.5)$ & $1.36(.55-3.36)$ & $.38(.08-1.72)$ & \\
\hline no & $63(87.5)$ & $9(12.5)$ & 1 & 1 & \\
\hline \multicolumn{6}{|l|}{ On ART } \\
\hline Yes & 123(89.1) & 15(10.9) & $.89(.34-2.31)$ & $.93(.28-3.07)$ & \\
\hline no & 64(90.1) & 7(9.9) & 1 & 1 & \\
\hline Insufficient milk & & & & & 0.013 \\
\hline Yes & 19(79.2) & $5(20.8)$ & $.38(.12-1.16)$ & $.14(.03-.65)^{*}$ & \\
\hline No & 168(90.8) & $17(9.2)$ & 1 & 1 & \\
\hline
\end{tabular}

Note: 1 - reference group

* Statistically significant $(p-$ value $<0.05)$ 
from Addis Ababa, Ethiopia (30.6\%) [15]. The Ethiopian Ministry of Health guideline on infant feeding recommendations of HIV exposed infants recommends EBF for the first 6 months and introducing complementary feeding at 6 months and continues breastfeeding until 12-18 months [21]. The difference may be also explained by the fact that in both the South African and Nigerian studies, infant formula was supplied free of charge unlike in the present study. Deep-rooted family and community norms make it difficult for mothers in Ethiopia as in most developing countries to choose ERF. In fact, choosing to use replacement feed is equivalent to announcing their HIV status, and the consequences of this are far reaching and could involve violence and divorce [22]. About $87 \%$ of the mothers had disclosed their HIV status to their spouses, and $65.6 \%$ of the mothers had disclosed their status to their family members. This number is found to be higher than what was reported in Nigeria (50\%) [19].

In multivariate analysis, disclosure of HIV status with their spouse, insufficient breast milk and occupational status were found to be independently associated with the recommended way of infant feeding practice. Mothers who disclose their HIV status to spouse were 7.7 times more likely to have the recommended way of infant feeding practice. Disclosure of HIV status greatly influenced infant feeding options of HIV positive mothers when the partner was aware of the HIV status of the mother and involved in the decision [23]. Having disclosed their status might have psychological benefits as they do not have to hide while formula feeding. Those daily laborers were 14.6 times more likely to have recommended way of infant feeding practice than government/private workers/merchants. Work overload may dispose merchants to practice MBF unconsciously.

The proportion of mothers practicing MBF (10.5\%) for the first 6 months of age was almost in line with studies conducted in Addis Ababa, Ethiopia (15.3\%) and South Africa (12.4\%) [15,17], but lower than from India (29\%) [18] and it was higher than what was reported from Cameroon (4.3\%) [24]. By tradition, mothers may consider breast milk is not enough for child growth and intend to use mixed feeding even though they have been informed. Mixed breast feeding has been shown to damage the intestinal lining of the gut in infants [14], leading to an increased risk of HIV transmission through breast milk $[9,14]$. In addition to MBF, duration of breast feeding is also strong determinant for HIV transmission through breast milk [13]. According to a study conducted in Zambia, early abrupt cessation of breast-feeding by HIV-infected women in a low-resource setting does not improve the rate of HIV-free survival among children born to HIV-infected mothers [25]. The recent guidelines of WHO stated that when ARVs are not available, mothers should be counseled to exclusively breastfeed in the first six months of life and continue breastfeeding thereafter unless environmental and social circumstances are safe for, and supportive of, replacement feeding [12]. Presence of insufficient breast milk was $85.7 \%$ times less likely to have recommended way of infant feeding practice. Due to the insufficiency of breast milk mothers might goes to mixed feeding.

In the present study, 193 (92.3\%) of women knew that mother to child transmission of HIV virus can occur during pregnancy, delivery and breast milk feeding which is a higher percentage compared to the findings (70\%) from a study done in South Africa [17]. This might be achieved due to the accessibility of mother support groups by preparing coffee ceremony for mothers in two weeks interval which is organized by NGO. However, without fostered counseling including information about the risks and benefits of breastfeeding, HIV-positive women may have made suboptimal infant feeding decisions (e.g., mixed feeding, underfeeding) based only on the knowledge that HIV can be transmitted by breastfeeding. In an effort to prevent HIV transmission to their infants, women may be unintentionally endangering their infants' health. This emphasizes the need for offering clear information about postpartum HIV transmission to all women seeking antenatal care.

Availability of supply, stigma of HIV/AIDS, insufficient breast milk and husband opposition were factors that influenced choice of infant feeding options by respondents. Higher percentage (13\%) of study participants complained that stigma of HIV/AIDS status affect their infant feeding option although the percentage is lower than studies conducted in Nigeria $(44 \%)$ [23,26]. This might be due to the cultural difference in accepting HIV/AIDS in the people of each country.

The study findings are limited in terms of overall generalization due to the small study sample size and it was health institution based. There is a possibility that study participants who received counseling on recommended way of infant feeding practice may simply answer questions accurately. This bias may underestimate the proportion of mixed feeding practice. Maternal since-birth recall of feeding patterns was also used which has its own limitations of long recall. Despite these limitations, we believe that our study findings provide essential input on infant feeding decisions.

\section{Conclusions}

The present study showed and identified that higher proportion $(89.5 \%)$ of the respondents used the recommended way of infant feeding practice. Mixed feeding (10.5\%), an undesirable practice in infant feeding, in the first 6 months of age were also reported. Major 
determinants of infant feeding practice were found to be disclosure of HIV status with their spouse, insufficient breast milk and occupational status. However, further advanced clinical trial studies have to be conducted in order to see the effect of different infant feeding practice for maternal viral transmission through breast milk.

\section{Abbreviations}

AFASS: Affordable, Feasible, Acceptable, Sustainable, and Safe; AIDS: Acquired Immune Deficiency Syndrome; ART: Anti Retroviral Therapy; EBF: Exclusive Breast Feeding; ERF: Exclusive Replacement Feeding; HIV: Human Immunodeficiency Virus; MBF: Mixed Breast Feeding; MTCT: Mother to Child Transmission; NGOs: Non Governmental Organizations; OR: Odds Ratio; PMTCT: Prevention of Mother to Child Transmission; SPSS: Statistical Packages for Social Sciences; UNAIDS: United Nations Program on HIV/AIDS; WHO: World Health Organization.

\section{Acknowledgements}

We acknowledge the financial and technical support provided by College of Medicine and Health Sciences, University of Gondar. The support obtained by the respective health institutions of Gondar town, data collectors and all the study participants and health personnel who participated were highly acknowledged.

\section{Authors' contributions}

DM: initiation of the study, design, implementation, analysis and writing. DW: design, implementation, analysis and writing. MG: implementation and COwriting. MT: design, implementation of the study and co-writing. All authors read and approved the final manuscript.

\section{Competing interests}

The authors declare that they have no competing interests.

Received: 9 August 2011 Accepted: 26 March 2012

Published: 26 March 2012

\section{References}

1. UNAIDS: Global summary of the AIDS epidemic. AIDS epidemic update 2008.

2. De Cock KM, Fowler MG, Mercier E, de Vincenzi I, Saba J, Hoff E, Alnwick DJ, Rogers M, Shaffer N: Prevention of mother-to-child HIV transmission in resource-poor countries: translating research into policy and practice. JAMA 2000, 283:1175-1182.

3. Guay L, Musoke P, Fleming T, Bagenda D, Allen M, Nakabiito C, Sherman J, Bakaki P, Ducar C, Deseyve M, Emel L, Mirochnick M, Fowler MG, Mofenson L, Miotti P, Dransfield K, Bray D, Mmiro F, Jackson JB: Intrapartum and neonatal single-dose nevirapine compared with zidovudine for prevention of mother-to-child transmission of HIV-1 in Kampala, Uganda: HIVNET 012 randomized trial. Lancet 1999, 354:795-802.

4. Newell M: Current issues in the prevention of mother-to-child transmission of HIV-1 infection. Trans R Soc Tropical Medicine and Hygiene 2006, 100:1-5.

5. UNAIDS/WHO: HIV and infant feeding: A Policy Statement developed collaboratively by UNAIDS, UNICEF and WHO UNAIDS/WHO, Geneva, Switzerland; 1998

6. Nduati R, John G, Mbori D, Richardson B, Overbaugh J, Mwatha A, NdinyaAchola J, Bwayo J, Onyango FE, Hughes J, Kreiss J: Effect of breastfeeding and formula feeding on transmission of HIV-1: a randomized clinical trial. JAMA 2000, 283:1167-1174.

7. Embree JE, Njenga S, Datta P, Nagelkerke NJ, Ndinya-Achola JO, Mohammed Z, Ramdahin S, Bwayo JJ, Plummer FA: Risk factors for postnatal mother-child transmission of HIV-1. AIDS 2000, 14:2535-2541.

8. Athena PKourtis, Denise JJamieson, Isabelle de Vincenzi, Allan Taylor, Michael CThigpen, Halima Dao, Timothy Farley, Mary Glenn Fowler: Prevention of human immunodeficiency virus-1 transmission to the infant through breastfeeding: new developments. American Journal of Obstetrics \& Gynecology 2007, 197:113-122.

9. Coovadia Hoosen M, Rollins Nigel C, Bland Ruth M, Kirsty Little, Anna Coutsoudis, Bennish Michael L, Marie-Louise Newell: Mother-to-child transmission of HIV-1 infection during exclusive breastfeeding in the first 6 months of life: an intervention cohort study. Lancet 2007, 369:1107-1116.

10. Coutsoudis A, Pillay K, Spooner E, Kuhn L, Coovadia HM: Influence of infant-feeding patterns on early mother-to-child transmission of HIV-1 in Durban, South Africa: a prospective cohort study. South African Vitamin A Study Group. Lancet 1999, 354:471-476.

11. Iliff P, Piwoz E, Tavengwa N, Zunguza CD, Marinda ET, Nathoo KJ, Moulton LH, Ward BJ, Humphrey JH: Early exclusive breastfeeding reduces the risk of postnatal HIV-1 transmission and increases HIV-free survival. AIDS 2005, 19:699-708.

12. WHO, UNICEF, UNFPA, UNAIDS: Guidelines on HIV and Infant Feeding 2010: Principles and recommendations for infant feeding in the context of HIV and a summary of evidence 2010.

13. Becquet R, Bland R, Leroy V, Rollins NC, Ekouevi DK, Coutsoudis A, Dabis F, Coovadia HM, Salamon R, Newell M: Duration. Pattern of Breastfeeding and Postnatal Transmission of HIV: Pooled Analysis of Individual Data from West and South African Cohorts. PLOS ONE 2009, 4:e7397.

14. Renaud Becquet, Ekouevi Didier K, Hervé Menan, Clarisse Amani-Bosse, Laurence Bequet, Ida Viho, François Dabis, Marguerite Timite-Konan, Valériane Leroy: Early mixed feeding and breastfeeding beyond 6 months increase the risk of postnatal HIV transmission. Preventive Medicine 2008, 47:27-33.

15. Maru Y, Haidar J: Infant feeding practice of HIV positive mothers and its determinants in selected health institutions of Addis Ababa, Ethiopia. Ethiopian Journal Health Development 2009, 23:107-114.

16. Ethiopian National Strategy on Infant and Young Child Feeding. 2004.

17. Rendani L, Karl P, Motlatso G, Khanyisa Phaweni: Infant-feeding practices and associated factors of HIV-positive mothers at Gert Sibande, South Africa. Acta Pædiatrica 2011, 100:538-542.

18. Suryavanshi N, Jonnalagadda S, Erande AS, Sastry J, Pisal H, Bharucha KE, Shrotri A, Bulakh PM, Phadke MA, Bollinger RC, Shankar AV: Infant feeding practices of HIV positive mothers in India. Journal of Nutrition 2003, 133:1326-1331.

19. Adejuyigbe E, Orji E, Onayade A, Makinde N, Anyabolu H: Infant feeding intentions and practices of HIV-positive mothers in Southwestern Nigeria. Journal of Human Lactation 2008, 24:303-310.

20. Fadnes LT, Engebretsen IM, Wamani H, Semiyaga NB, Tylleskär T, Tumwine JK: Infant feeding among HIV-positive mothers and the general population mothers: comparison of two cross-sectional surveys in Eastern Uganda. BMC Public Health 2009, 9:124.

21. Guidelines for Prevention of Mother-to-Child Transmission of HIV in Ethiopia. Federal HIV/AIDS Prevention and Control Office, Federal Ministry of Health 2007.

22. Adejuyigbe $\mathrm{E}$, Odebiyi A: Parental HIV serodiscordance: implications for the care of the HIV seropositive child in a poor-resource setting. AIDS Care 2006, 18:537-543.

23. Mohammed A, Shehu AU, Aliyu AA, Zoaka Al: Infant feeding options, practices and determinants of HIV-positive mothers in Abuja, Nigeria. Niger Medical Journal 2010, 51:14-17.

24. Njom Nlend A, Penda I, Same Ekobo C, Tene G, Monny Lobe M, Tsague L, Macauley I, Zekeng L, Engozo'o A: International Conference on AIDS (15th:2004: Bangkok, Thailand). Factors associated with infant feeding choices of HIV positive mothers in urban areas. Cameroon Int Conf AIDS 2004, 15:11-16.

25. Kuhn L, Aldrovandi GM, Sinkala M, Kankasa C, Semrau K, Mwiya M, Kasonde P, Scott N, Vwalika C, Walter J, Bulterys M, Tsai W, Thea DM: Effects of Early, Abrupt Weaning on HIV-free Survival of Children in Zambia. N Engl J Med 2008, 359:130-141.

26. Oladokun R, Brown B, Osinusi K: Infant-feeding pattern of HIV-positive women in a prevention of mother-to-child transmission (PMTCT) programme. AIDS Care 2010, 22:1108-1114.

Pre-publication history

The pre-publication history for this paper can be accessed here: http://www.biomedcentral.com/1471-2458/12/240/prepub

doi:10.1186/1471-2458-12-240

Cite this article as: Muluye et al:: Infant feeding practice and associated factors of HIV positive mothers attending prevention of mother to child transmission and antiretroviral therapy clinics in Gondar Town health institutions, Northwest Ethiopia. BMC Public Health 2012 12:240. 